This is a pre-copy-editing, author-produced PDF of an article accepted for publication in The British Journal of Occupational Therapy following peer review.

The definitive publisher-authenticated version is:

Watson J; Chapman J; Adams J; Ummey Hamila N (2006) Occupational Therapy Students' Approaches to Learning: Considering the Impact of Culture. British Journal of Occupational Therapy, 69(12), $p$ 548-555.

\title{
Occupational Therapy Students' Approaches to Learning: Considering the Impact of Culture
}

\author{
Jo Watson, Judith Chapman, Jo Adams, Ummey Hamida Nila
}

\author{
Scholarly Paper \\ Education \\ Word Count: 4044 \\ Jo Watson (MSc, BAppSc (OT), BAOT) \\ Lecturer in Occupational Therapy \\ School of Health Professions and Rehabilitation Sciences \\ University of Southampton \\ Judith Chapman (MSc, MCSP) \\ Lecturer in Physiotherapy \\ School of Health Professions and Rehabilitation Sciences \\ University of Southampton \\ Jo Adams (PhD, MSc, DipCOT, BAOT) \\ Lecturer in Occupational Therapy \\ School of Health Professions and Rehabilitation Sciences \\ University of Southampton

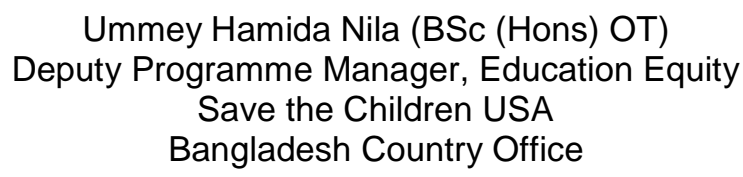 \\ For Correspondence: \\ Jo Watson \\ Lecturer in Occupational Therapy \\ School of Health Professions and Rehabilitation Sciences \\ University of Southampton \\ Highfield \\ Southampton \\ Hampshire SO17 1BJ \\ Ph: 02380595303 \\ e-mail: jdw@soton.ac.uk \\ fax: 02380595301
}




\section{Abstract}

Learning approaches describe the way individuals approach tasks or learning situations and are influenced by individual characteristics and specific learning contexts. Cultural factors are likely to impact on various aspects of learning, yet the literature disagrees over the extent to which culture influences approaches to learning. With increasing cultural diversity in student cohorts and the contributions of western therapists to occupational therapy programmes in developing nations, this issue is worthy of exploration within the context of pre-registration education.

The Approaches to Study Inventory (ASI) was used to explore differences in the approaches to learning of UK and Bangladeshi occupational therapy students studying in their home countries. Significant differences between the groups revealed that the Bangladeshi students display both stronger tendencies for deep approaches to learning ( $p$ $<0.05)$ and for less integrated superficial approaches to learning $(p<0.05)$. This apparent contradiction required careful consideration.

There is no single 'correct' way to learn. This study's results reinforce the need for cultural sensitivity in not only clinical, but educational contexts. The cultural biases underpinning the constructs of deep and superficial learning approaches are explored. Educators are encouraged to recognise the potential for culture to influence how students engage within the learning environment and how they themselves construct the learning opportunities. 


\section{Introduction}

The aim of this cross-sectional study was to examine and compare the approaches to learning adopted by occupational therapy students studying in the UK and those studying in Bangladesh. An individual's approach to learning describes the manner in which s/he approaches tasks or learning situations; and is influenced by characteristic traits of the individual and the specific context in which learning occurs (Cassidy 2004, Desmedt and Valcke 2004). Cultural factors are likely to impact on individual preferences and values, behaviour, attitudes and interaction within a learning environment; yet there is disagreement in the literature regarding the extent to which culture influences approaches to learning (Dunn and Wallace 2004, Kennedy 2002, Kember and Gow 1991). With increasing demand from government and professional bodies to expand the cultural diversity of the health care workforce (Department of Health (DH) 2000, College of Occupational Therapists (COT) 2004); the potential impact of culture on approaches to learning may have implications for the design and delivery of undergraduate programmes.

\section{Literature Review}

A search for relevant literature was undertaken using the International ERIC, Web of Science, Zetoc , PsychInfo, CINAHL, AMED, EMBASE and MEDLINE databases between 1975 and 2005, with key words 'learning styles', 'learning approaches' , 'learning preferences', 'occupational therapy students', 'international students', 'culture', and 'crosscultural learning'.

Research into differing approaches to learning and motivation to learn originates from the field of psychology and has been evident over the last four decades. Readers are directed to Cassidy (2004) and Desmedt and Valcke (2004) for excellent reviews of theory, terminology and models regarding learning approaches and preferences. 
Early research conducted by Marton and Säljö (1976) identified two types of learning that are still recognised today: a surface approach to learning involving rote memorisation of specific information; and a deep approach in which the student seeks meaning and is actively involved in developing a conceptual understanding and application of information through critical thinking and problem solving. A third, strategic approach to learning has also been identified, in which students focus their attention on the achievement of high grades, utilising a variable approach to learning selected on the basis of its potential to achieve success in a given assessment context (Newble and Entwistle 1986).

The literature suggests that age and individual characteristics influence approaches to learning (Jamison and Dirette 2004, Hardigan and Cohen 2003, Aaron and Skakun 1999, Cavanagh and Coffin 1994). There is also agreement that educational strategies and teaching methods influence the depth and successful application of learning (Ramsden 2003, Biggs 1999, Curry 1999, Newble and Clarke 1986, Newble and Entwistle 1986). Studies by Curry (1999) and Newble and Entwistle (1986) suggest that the match between learning environment, teaching strategies and preferred learning approaches of medical students exerts an important influence on the success of student outcomes.

It is the deep approach to learning that educators are more likely to encourage because it is the most conducive to successful academic and professional development. In a longitudinal study of two cohorts of medical students, Arnold and Feighny (1995) demonstrated that deep approaches to learning had a positive correlation with both high academic achievement and better clinical performance.

\section{Measuring Learning Styles}

There have been many attempts to investigate approaches to learning and many instruments developed (Cassidy 2004, Desmedt and Valcke 2004). An instrument focussing particularly on identifying the level and depth of learning was developed by 
Entwistle and colleagues (Entwistle et al 1979; Entwistle and Ramsden 1983). The Approaches to Studying Inventory (ASI) records both student motivation and information processing during a learning activity. It identifies three approaches to learning: deep approaches in which understanding is sought; surface approaches with an intention to memorise and reproduce; and strategic approaches with a focus on the demands of assessments and an intention to excel. Responses are provided on a five point Likert scale where the most positive responses are given a value of 4; and statements producing least agreement are given a value of zero (Entwistle and Ramsden 1983).

The ASI has been used extensively in educational research in the UK and is known to have moderately sound psychometric properties (Cassidy 2004, Duff 2000). The ASI has been adapted over time and there are several shorter inventories that have emerged. Testretest reliability has been documented as ranging from moderate to good with reliability coefficients ranging from 0.40 to 0.78 on a 30 item version (Arnold and Feighny 1995). The primary dimensions examined in the ASI are summarised in Table 1.

\section{Table One: Summary of the Dimensions of the ASI}

\section{The Impact of Culture on Learning Styles}

The need for clinicians to operate as culturally aware and sensitive practitioners has earned an increasingly high profile in recent years (Adams 2003); and is accompanied by recognition of the need to incorporate greater attention to cultural diversity within the curriculum of pre-registration programmes (Awaad 2003, Chaing and Carlson 2003, Cheung et al 2002, Stewart 2002, Yuen and Yau 1999). However, the need to be culturally aware is equally relevant to the pedagogical foundations upon which these pre-registration programmes are established. 
Culture is viewed as the shared, learned behaviours, or the ways of life adopted by groups of humans; incorporating the attitudes, ideals, values and social rules in which individuals ground and interpret their actions and experiences (Kennedy 2002, Tweed and Lehman 2002). De Vita (2001) suggests that by influencing the way individuals perceive, organise and process information, the way they interact and communicate with others and the way they understand, organize and generate knowledge and solve problems, culture is inextricably linked to learning approaches and preferences. Cultural factors are likely to have an impact on student preferences for thinking, behaving and relating to others within classroom or learning situations; just as they are likely to influence the manner in which the educator perceives and constructs the learning environment, the learning tasks and the teaching methods adopted (Kennedy 2002, Tweed and Lehman 2002, De Vita 2001).

There is disagreement in the literature regarding the extent to which culture is perceived to exert an influence on the development of individual approaches to learning. Da Vita (2001) reports on a small number of studies dating from 1975 to 1996 that support the notion of culture influencing learning approaches. His own research demonstrated that home students from the UK had a marked preference for active, sequential information processing; while a heterogeneous international student sample preferred a more reflective, intuitive approach. More recently, Dunn and Wallace (2004) considered the experiences of Australian academics engaged in the delivery of an international degree in Singapore. They found that students from Singapore value formal relationships with tutors and lecturers as a way of demonstrating their respect for the knowledge and expertise of academics. They further found that there were cultural clashes in the understanding of students and academics in relation to appropriate mechanisms for demonstrating learning; with Singaporean students having a tendency to adopt superficial approaches of memorising and repeating verbatim large sections of text without reference to appropriate citations. 
Dunn and Wallace (2004) and Kennedy (2002) consider the apparent reluctance of students form Singapore and Hong Kong (respectively) to participate verbally in class, contributing to a perception of them as passive learners. Dunn and Wallace (2004) suggest a preference to learn from 'masters' rather than challenge them, which Kennedy (2002) relates to deeper cultural imperatives such as the need to show proper respect for age and rank. Loss of face or causing another to lose face is considered shameful and selfish, so questioning or criticising a lecturer is discouraged; as is committing oneself for fear of being wrong or revealing a lack of understanding in front of others.

The perception of students from Pacific Rim countries as highly deferential towards teachers and overly reliant upon rote learning is debated in the literature (Dunn and Wallace 2004, Lengkanawati 2004, Kennedy 2002, Harris 1995, Kember and Gow 1991, Kember and Gow 1990). Using Willings' Learning Styles Inventory, Lewis (1996) found that Indonesian tertiary students displayed approaches that spanned the full range of learning orientations. Kennedy (2002) and Kember and Gow (1991, 1990) concluded that the approaches to learning of Hong Kong students are less dissimilar to those of Western students than has been suggested; and is more likely to be a function of the pedagogical styles to which they have been exposed, than to specific cultural issues.

Pratt et al (1999) add a further dimension to the debate by focusing on cultural variations in the understanding of the concepts of learning and teaching. The results of their survey of Hong Kong Chinese faculty and students, and expatriate Western faculty found marked differences between the two groups. The Hong Kong Chinese group spoke of memorising as being a purposeful and appropriate way of mastering the basics as a first step within a broader sequence of learning processes. Repetition and drill is seen to increase attention to detail and therefore deepen understanding of material which is subsequently applied to problems or situations before being taken on to higher levels of analysis and synthesis. 
Distinction is drawn between memorisation as part of this more extensive process and superficial rote-learning which lacks accompanying understanding.

Hong Kong Chinese faculty believed their primary responsibility to be taking students systematically through a highly structured, sequential set of tasks focussed on examination success; which would secure access to the further educational opportunities associated with higher social status and earning potential. In contrast, expatriate Western faculty viewed their role as facilitators of independent student learning; and portrayed an effective classroom as one in which students learned to think qualitatively differently (as distinct from simply learning more) through actively challenging rather than receiving the knowledge of the teacher and text (Pratt et al 1999).

Tweed and Lehman (2002) have offered a framework for understanding the approaches to learning of Western and Chinese students which moves away from the concepts of deep and superficial approaches to learning, and instead considers Confucian and Socratic approaches. The Confucian-oriented approach focuses on effortful acquisition of essential knowledge from experts; which is deemed to be linked with personal transformation and self-improvement. Socratic approaches focus on overt and private questioning of the self and others, the expression of personal hypotheses and engagement with self-directed tasks in the pursuit of self-generated knowledge. The framework suggests that culturally Chinese students tend to view effort as being central to learning; while culturally Western students tend to consider that innate ability is the central issue. The framework mirrors many of the concepts that are raised in the literature; but does not label them as desirable or undesirable; deep or superficial. The authors' hypothesis is that in some contexts, the Confucian approach to learning is the most adaptive; while in other circumstances, the Socratic approach is. 
Exploration of the potential impact of culture on the approaches to learning adopted by occupational therapy students is not yet evident in the literature. The contributions of culturally Western educators to the educational programmes of developing countries, and efforts to increase diversity of occupational therapy student populations in Western countries raise the potential of a significant mismatch in educational expectations of teacher and student; which could impact on student outcomes.

The lack of agreement in the literature justified this small cross-sectional study, which aimed to examine and compare the approaches to learning adopted by undergraduate occupational therapy students studying in the UK and those studying in Bangladesh.

\section{Research Questions}

Are there differences in the approaches to learning adopted by occupational therapy students studying at the University of Southampton in the UK and those studying at the Bangladesh Health Professions Institute, as measured by the short Approaches to Study Inventory (ASI) (40 item)?

\section{Ethical Issues}

Approval for the study was awarded by established Ethics Committees at both of the participating institutions prior to any data collection. Students were advised that they were under no obligation to complete the questionnaire and that all responses would remain anonymous. The questionnaire was administered by a member of the teaching staff working at each institution who was not directly involved in the assessment of students. The students scored their own individual questionnaire responses. Data were inputted for analysis by an independent researcher. 


\section{Methodology}

\section{Settings:}

The Southampton programme is a three year full-time undergraduate programme. The Bangladesh programme comprises five years of undergraduate training, which includes one year full-time internship in the fifth year. In order to aid handling and comparison of data, questionnaires completed by students from years three and four of the Bangladesh programme were combined and are referred to as 'Final Year'.

\section{Data collection tool:}

The short 40 item ASI self report questionnaire was distributed to students in all three years of the undergraduate $\mathrm{BSc}(\mathrm{Hons})$ occupational therapy programme at the University of Southampton $(\mathrm{N}=138)$ and to students in all four years of the $\mathrm{BSc}(\mathrm{Hons})$ occupational therapy programme at the Bangladesh Health Professions Institute $(\mathrm{N}=46)$. Students were invited to complete and score the questionnaire, which took no more than ten minutes, at the end of a teaching session.

\section{Data Analysis}

Scored data from the questionnaires were inputted into an SPSS data base (SPSS version 11.0 Chicago Inc). Descriptive statistics (mean and standard deviation) present the summary scores for the primary ASI subscales for each year group and the independent samples T-test identifies any significant differences between the Bangladeshi and Southampton student groups.

\section{Results}

At year one there are statistically significant differences between the Bangladeshi and Southampton students in achieving orientation $(p=0.001)$, comprehension learning $(p=0.001)$, operation learning $(p=0.026)$, versatility $(p=0.001)$ and prediction of success $(p=0.008)$. The Southampton students scoring statistically significantly lower on all of these 
dimensions. There are no statistically significant differences in reproducing orientation; meaning orientation; learning pathologies or elaboration between the two groups of students (see Table Two).

\section{Table Two: Summary of Results}

Within year two, there are statistically significant differences between the Bangladeshi and Southampton students in the dimensions of meaning orientation $(p=0.033)$; comprehension learning $(p=0.041)$; operation learning $(p<0.001)$; versatility $(p=0.020)$ and learning pathologies $(p=0.001)$. There were no statistically significant differences in the dimensions of achieving orientation; reproducing orientation; prediction of success and elaboration (see Table Two).

In final year students there are statistically significant differences between the Bangladeshi and Southampton students in the dimensions of achieving orientation $(p<0.001)$, meaning orientation ( $p=0.001)$, comprehension learning $(p<0.001)$, operation learning $(p<0.001)$, versatility $(p=0.003)$, learning pathologies $(p<0.001)$ and elaboration $(p<0.001)$. There were no statistically significant differences in the dimensions of reproducing orientation, prediction of success or elaboration (see Table Two).

\section{Discussion}

The aim of this study was to explore any differences in the approaches to learning adopted by occupational therapy students studying in a UK environment and those studying in Bangladesh. There are statistically significant differences between the two groups in a number of dimensions in each year of study. For every dimension within each year of study, the Bangladeshi students recorded higher mean scores than the Southampton students, although not all dimensions reached statistical significance. 
In Year one, Bangladeshi students consistently demonstrated a greater tendency for deep learning than the Southampton students, recording mean scores that were statistically significantly higher for comprehension learning, versatility and prediction of success: all dimensions associated with deep learning. The accompanying statistically significantly higher mean score for achieving orientation would seem to indicate that these students are also geared towards maximising their success in assessments. The statistically significantly higher mean score in operation learning is indicative of a step-wise approach to learning. However, consideration of this result with those that are indicative of deep approaches reinforces that this structured technique can be viewed as a positive learning strategy.

Second year Bangladeshi students again tended to focus more on strategies associated with deep learning than their Southampton counterparts; with statistically significantly higher mean scores in meaning orientation, comprehension learning and versatility. The statistically significant results that do not follow this trend in the year two data are the Bangladeshi students' higher scores in operation learning accompanied on this occasion by higher scores in learning pathologies.

As indicated in Table One, operation learning can be associated with either deep or superficial learning, depending on whether the step-wise approach is supported by sound evidence before generalisations are accepted. This study's results may be interpreted in a number of ways. They may indicate that a proportion of the second year Bangladeshi group were using the step-wise approach without integrating it with the meaning and understanding of some of their class mates; resulting in high scores in both the dimensions associated with deep learning and learning pathologies. The results may reflect anomalies thrown up by a small sample size; but it is also possible that English is a second or even third language for some Bangladeshi participants, contributing to difficulties in accurately 
interpreting the subtle coding of the English language and deciphering the nuances of the task and specific adjectives used (Dunn and Wallace 2004, Kember and Gow 1991).

In the final year, Bangladeshi students again show a statistically significantly higher achieving orientation mean than their Southampton counterparts, indicative of a greater focus on success in assessments that was also evident in the year one data. This was accompanied by statistically significantly higher scores in the dimensions of meaning orientation, comprehension learning, versatility, elaboration and operation learning; all of which are indicative of deep approaches to learning. The one result that is again at odds with the above trend is the statistically significantly higher mean score for learning pathologies.

It is important to understand that any statistically significant results found represent differences between the Bangladeshi students and the Southampton students; rather than being a significant tendency within the Bangladeshi group alone. The results have consistently revealed a statistically significantly higher tendency for deep learning amongst the Bangladeshi students than the Southampton students.

These results are comparable with those of Kember and Gow (1991) who found that students in Hong Kong displayed deeper approaches to learning that their Australian counterparts. They also mirror the results of Ramburuth (2000) who found frequent use of both surface and deep approaches by international students studying in an Australian University; although, in that study, all participants were experiencing a western style of higher education. Pratt et al (1999) provide a clear account of the approach to learning both accepted and expected by Hong Kong Chinese faculty and students; in which memorisation of foundation knowledge is used not only to enable students to develop a framework on which to build and expand their knowledge and understanding of a topic, but to encourage greater attention to detail and deepen understanding of material. Clearly the 
cultural nuances of Hong Kong Chinese approaches to learning cannot be directly attributed to the learning environment in Bangladesh associated with this study; but the data could be suggesting evidence of a similar principle.

Deep and superficial approaches to learning have generally been viewed as mutually exclusive constructs; however, the interweaving of memorisation which is generally associated with superficial learning, with the understanding which is associated with a deep approach, draws this assumption into question (Ramburuth 2000). Step-wise learning may appear to be indicative of a superficial approach; but utilising these steps to develop context and meaning can actively progress learning to a deeper level. What looks at first like a learning pathology may simply reflect a culturally biased view of learning as reflected in the tool. Whilst the ASI has been used extensively within western cultures, its reported use within non-western cultures is limited; and validity and reliability within specific non-western cultural groups must be questionable without further research (Dunn and Wallace 2004, Dangwal and Mitra 1998, Kember and Gow 1990). Furthermore, the constructs of deep and superficial learning may not be compatible with the learning behaviours and values evident in some cultural groups (Ramburuth 2000).

There is no single 'correct' way to learn. In preference to falling into the trap of making judgements about the effectiveness or desirability of different approaches to learning, educators need both to be aware of the potential for culture to influence student preferences and expectations; and to introduce sufficient flexibility into their approach to teaching to acknowledge the variations that may encounter (Dunn and Wallace 2004, Kennedy 2002, De Vita 2001, Ramburuth 2000, Kember and Gow 1991). Some argue that in sensitively doing so, educators will not only appeal to a broad range of preferences, but potentially stretch individual students beyond their established styles and comfort zones; enabling them to develop more adaptive learning strategies and approaches, and facilitating a greater capacity to engage in a variety of lifelong learning and professional 
development opportunities in the future (Kennedy 2002, De Vita 2001). Given that the data from this study indicates that students from the Bangladesh School adopt deeper approaches to learning than those from the Southampton School; careful consideration needs to be given to which approaches are encouraged or discouraged and how they are utilized and developed.

\section{Limitations}

The findings of this study need to be viewed in light of the generally small sample sizes. Combining the data from years three and four of the Bangladeshi programme may have had a further confounding effect. Given the cross-sectional nature of the study it is not possible to measure changes within the individual programmes between the first and final years. In order to explore any such changes, a longitudinal study following a single cohort would be required; and could perhaps form the basis of further work in this area.

Since this data was collected, the ASI has been superseded by revised versions which have updated the questions and terminology used; although issues already discussed regarding the cultural appropriateness of the tool would not have been avoided by using the most recent version. Nevertheless, the findings of this study do raise some interesting issues which help to start raising awareness of the need to consider the influence of culture on approaches to learning.

\section{Conclusion}

Cultural sensitivity has been established as an essential characteristic of all occupational therapists (COT 2005). In line with government and professional initiatives, there is evidence of a slow increase in the cultural diversity of pre-registration student cohorts in the UK (COT 2003). Where students have previously been educated within the UK, the impact of culture may not be as marked; but an awareness of the range of approaches to learning is beneficial to the successful planning and delivery of any syllabus. 
It is short-sighted to consider students' approaches to learning independently of the learning environment in which they find themselves. Good practice with regard to the learning and teaching strategies implemented by educators, such as the avoidance of didactic modes of delivery, heavy workloads and assessment strategies that reward superficial approaches to learning, have all been shown to have a significant impact on study behaviours and to enhance student learning (Ramsden 2003, Biggs 1999, Curry 1999, Newble and Entwistle 1986, Newble and Clarke 1986). However, it is also important to recognise that learning inevitably occurs within a context likely to incorporate a framework constructed by the educator with reference to their own learning and teaching preferences or styles, as well as local social and pedagogical cultures. Recognising and acknowledging similarities and differences in approaches to learning in a cultural context makes a further contribution towards effectively managing diversity in the classroom. Ramburuth (2000) advocates cross-cultural training programmes for staff and academic acculturation programmes for international students. Whilst acknowledging differences that are educationally meaningful, concerted efforts should be made to avoid the unnecessary stereotyping of groups that has at times been evident in the literature (Swanson 1995, Lewis 1996); and to acknowledge that cultural groups are not themselves homogenous (Tweed and Lehman 2002).

This study highlights clear implications for culturally western therapists choosing to work in non-western environments; perhaps particularly educators who travel to developing countries to contribute to the development or delivery of therapy training programmes. Importing a western approach to learning and teaching will not necessarily fit with the approaches and expectations of Schools founded within different cultures. However, recognition of the influence of culture on approaches to learning is equally applicable to all clinicians who are engaged in the education of patients and clients, or the education of students on practice placements. 
In keeping with the abiding philosophies underpinning the profession, cultural awareness should be considered a universally desirable characteristic evident in all aspects of the training and practice of occupational therapists, not reserved solely for clinical scenarios.

\section{Acknowledgements}

The authors would like to thank all of the students who participated in this study, and the anonymous reviewers of earlier drafts of this paper. 


\section{References}

Aaron, S and Skakun, E (1999) Correlation of students' characteristics with their learning styles as they begin medical school. Academic Medicine 74(3): 260-262.

Adams J (2003) Cultural Competency [Letter to the Editor]. British Journal of Occupational Therapy 66(10): 490 .

Arnold, L and Feighny, KM (1995) Students' general learning approaches and performances in medical school: A longitudinal study. Academic Medicine 70(8): 715-722.

Awaad, T (2003) Culture, cultural competency and occupational therapy: A review of the literature. British Journal of Occupational Therapy 66(8): 356-362.

Barris, R; Kielhofner, G and Bauer, D (1985) Learning preferences, values and student satisfaction. Journal of Allied Health 14(1): 13-23.

Biggs, J (1999) Teaching for Quality Learning at University. Buckingham: The Society for Research into Higher Education \& Open University Press.

Cassidy, S (2004) Learning Styles: An overview of theories, models and measures. Educational Psychology 24(4): 419-444.

Cavanagh, SJ and Coffin, DA (1994) Matching instructional preference and teaching styles: a review of the literature. Nurse Education Today 14: 106-110. 
Chaing, M and Carlson, G (2003) Occupational therapy in multicultural contexts: Issues and strategies. British Journal of Occupational Therapy 66(12): 559-567.

Cheung, Y; Shah, S and Muncer, S (2002) An exploratory investigation of undergraduate students' perceptions of cultural awareness. British Journal of Occupational Therapy 65(12): $543-550$

College of Occupational Therapists (2005) Code of Ethics and Professional Conduct. London: College of Occupational Therapists.

College of Occupational Therapists (2004) College of Occupational Therapists: Strategic Vision and Action Plan for Lifelong Learning. British Journal of Occupational Therapy 67(1): 20-28.

College of Occupational Therapists (2003) Ten Year Review of Occupational Therapy Student Numbers in the United Kingdom. London: College of Occupational Therapists.

Curry L (1999) Cognitive and learning styles in medical education. Academic Medicine 74(4): 409-412.

Dangwal, R and Mitra, S (1998) Construction and validation of a Learning Styles Inventory test for use in India. Available at: www.geocities.com/SoHo/1718/docs/lstyles.html . Accessed: 12th February 2003.

Department of Health (2000) Meeting the Challenge: A Strategy for the Allied Health Professions. London: Department of Health. 
Desmedt, E and Valcke, M (2004) Mapping the Learning Styles "Jungle": An overview of the literature based on critical analysis. Educational Psychology 24(4): 445-464.

De Vita, G (2001) Learning Styles, Culture and Inclusive Instruction in the Multicultural Classroom: A Business and Management Perspective. Innovations in Education and Teaching International: 165-74.

Duff, A (2000) Learning styles measurement: the revised Approaches to Studying Inventory (RASI). Bristol Business School Teaching and Research Review: Issue 3.

Dunn, L and Wallace, M (2004) Australian academics teaching in Singapore: striving for cultural empathy. Innovations in Education and Teaching International 41(3): 291-304.

Entwistle, NJ; Hanley, M and Hownsell, DJ (1979) Identifying distinctive approaches to studying. Higher Education 8: 365-380.

Entwistle, NJ and Ramsden, P (1983) Understanding Student Learning. London: Croom Helm.

Hardigan, PC and Cohen, SR (2003) A comparison of learning styles among seven health professions: implications for optometric education. The Internet Journal of Allied Health Sciences and Practice 1(1), Available at: http://ijahsp.nova.edu/articles/1vol1/HardiganCohen.html, Accessed 24/02/05.

Harris, R (1995) Overseas students in the United Kingdom university system. Higher Education 29: 77-92. 
Jamison, PW and Dirette, D (2004) Personality type in occupational therapy students: Implications for teaching and learning strategies. Occupational Therapy in Health Care 18(1-2): 83-98.

Kember, D and Gow, L (1990) Cultural Specificity of Approaches to Study. British Journal of Educational Psychology (60): 356 - 363.

Kember, D and Gow, L (1991) A Challenge to the Anecdotal Stereotype of the Asian Student. Studies in Higher Education16(2): 117-128.

Kennedy, P (2002) Learning cultures and learning styles: myth-understandings about adult (Hong Kong) Chinese learners. International Journal of Lifelong Education 21(5): 430-445.

Lengkanawati, NS (2004) How learners from different cultural backgrounds learn a foreign language. Asian EFL Journal 6(1). Available at: http://www.asian-efljournal.com/04 nsl.php Accessed: 20/02/0420th

Lewis, R (1996) Indonesian students' learning styles. English Australia Journal 14(2): 2732.

Marton, F and Säljö, R (1976) On qualitative differences in learning; I: outcome and process. British Journal of Educational Psychology 46: 4-11.

Newble, DI and Clarke, R (1986) The approaches to learning of students in a traditional and an innovative problem-based medical school. Medical Education 20: 267-273.

Newble, DI and Entwistle, NJ (1986) Learning styles and approaches: implications for medical education. Medical Education 20: 162-175. 
Pratt, DD, Kelly M and Wong WSS (1999) Chinese conceptions of 'effective teaching' in Hong Kong: Towards culturally sensitive evaluation of teaching. International Journal of Lifelong Education 18(4): 241-258.

Ramburuth, P (2000) Cross Cultural Learning Behaviour in Higher Education: Perceptions versus Practice. Paper originally presented at the $7^{\text {th }}$ International Literacy \& Education Research Network Conference on Learning, RMIT University, Melbourne, 5-9 July 2000. Available at: http://ultibase.rmit.edu.au/Articles/may01/ramburuth1.html Accessed: $03 / 11 / 2004$

Ramsden, P (2003) Learning to Teach in Higher Education ( $\left.2^{\text {nd }} E d\right)$. London: Routledge Falmer.

Stewart, M (2002) Cultural competence in undergraduate healthcare education: Review of the issues. Physiotherapy 88(10): 620-629.

Swanson, LJ (1995) Learning Styles: A Review of the Literature. Educational Research Information Centre document No. ED 387067.

Tweed, RG and Lehman, DR (2002) Learning Considered within a Cultural Context: Confucian and Socratic Approaches. American Psychologist 57(2): 89-99.

Yuen, HK and Yau, MK (1999) Cross-cultural awareness and occupational therapy education. Occupational Therapy International 6(1): 24-34. 
Table One: Summary of the Dimensions of the ASI

\begin{tabular}{|l|l|}
\hline Meaning orientation & Associated with deep learning \& an intrinsic interest in the subject. \\
\hline Reproducing orientation & $\begin{array}{l}\text { Contains the features of a superficial approach, including rote } \\
\text { learning. }\end{array}$ \\
\hline Achieving orientation & $\begin{array}{l}\text { A strategic orientation aimed at the achievement of successful } \\
\text { assessment outcomes. }\end{array}$ \\
\hline Operation learning & $\begin{array}{l}\text { Involves a step-wise approach \& tends to be associated with } \\
\text { superficial learning. Becomes part of a deep approach to learning } \\
\text { only when combined with an acceptance of generalisations when } \\
\text { supported by sound evidence. }\end{array}$ \\
\hline Comprehension learning & $\begin{array}{l}\text { Adopts a broad focus considering interconnection of ideas \& } \\
\text { previous knowledge; a feature of deep learning. }\end{array}$ \\
\hline Versatility & $\begin{array}{l}\text { Displayed by the most successful learners who are able to adopt } \\
\text { either comprehension or deep operation learning as appropriate to } \\
\text { the individual learning task. }\end{array}$ \\
\hline $\begin{array}{l}\text { Learning } \\
\text { pathologies }\end{array}$ & $\begin{array}{l}\text { Incorporates the step-wise element of operation learning but fails } \\
\text { to understand the inter-relationship between concepts \& ideas, } \\
\text { developing a limited view of the topic. }\end{array}$ \\
\cline { 2 - 3 } Prediction of Success & $\begin{array}{l}\text { Superficial use of comprehension learning in which premature } \\
\text { conclusions are drawn without appropriate supporting evidence. }\end{array}$ \\
\hline Elaboration & $\begin{array}{l}\text { Combines various subscales: the competitive element of } \\
\text { achievement motivation, learning for comprehension \& meaning } \\
\text { along with the emphasis on facts \& logical analysis found in } \\
\text { versatility; moderated by the score for learning pathologies. }\end{array}$ \\
\hline \begin{tabular}{l} 
The ability to link material in order to expand understanding. \\
\hline
\end{tabular} &
\end{tabular}

(Adapted from Newbel and Entwistle 1986, Newbel and Clarke 1986) 
Table Two: Summary of Results

Figures are shown as mean (standard deviation) unless stated otherwise.

\begin{tabular}{|c|c|c|c|c|c|c|c|c|c|}
\hline Student Group & $\begin{array}{l}\mathrm{B}: \mathrm{Y} 1 \\
\mathrm{n}=9\end{array}$ & $\begin{array}{l}\text { S: Y1 } \\
n=49\end{array}$ & $\begin{array}{l}\text { B/w group } \\
\text { difference }\end{array}$ & $\begin{array}{l}\mathrm{B}: \mathrm{Y} 2 \\
\mathrm{n}=8\end{array}$ & $\begin{array}{l}\mathrm{S}: \mathrm{Y} 2 \\
\mathrm{n}=52\end{array}$ & $\begin{array}{l}\text { B/w group } \\
\text { difference }\end{array}$ & $\begin{array}{c}B: Y 3+4 \\
n=29\end{array}$ & $\begin{array}{l}\text { S: Y3 } \\
\mathrm{n}=37\end{array}$ & $\begin{array}{l}\text { B/w group } \\
\text { difference }\end{array}$ \\
\hline Age & $\begin{array}{l}19.75 \\
(0.89) \\
\end{array}$ & $\begin{array}{l}23.75 \\
(6.87) \\
\end{array}$ & $\begin{array}{c}\text { Independent } \\
\text { Samples T-test }\end{array}$ & $\begin{array}{l}21.25 \\
(1.04) \\
\end{array}$ & $\begin{array}{l}23.02 \\
(6.51) \\
\end{array}$ & $\begin{array}{c}\text { Independent } \\
\text { Samples T-test }\end{array}$ & $\begin{array}{l}23.36 \\
(1.45) \\
\end{array}$ & $\begin{array}{l}25.91 \\
(6.40) \\
\end{array}$ & $\begin{array}{c}\text { Independent } \\
\text { Samples T-test }\end{array}$ \\
\hline \multicolumn{10}{|l|}{ ASI Dimensions: } \\
\hline $\begin{array}{l}\text { Achieving } \\
\text { orientation }\end{array}$ & $\begin{array}{l}20.13 \\
(1.55)\end{array}$ & $\begin{array}{l}17.42 \\
(2.14)\end{array}$ & $\mathrm{p}=0.001^{\star *}$ & $\begin{array}{l}19.63 \\
(2.45)\end{array}$ & $\begin{array}{l}17.87 \\
(2.24)\end{array}$ & $\mathrm{p}=0.061$ & $\begin{array}{l}19.62 \\
(2.50)\end{array}$ & $\begin{array}{l}17.00 \\
(2.72)\end{array}$ & $\mathrm{p}<0.001^{* \star}$ \\
\hline $\begin{array}{l}\text { Reproducing } \\
\text { orientation }\end{array}$ & $\begin{array}{l}15.88 \\
(1.55)\end{array}$ & $\begin{array}{l}16.00 \\
(2.39)\end{array}$ & $\mathrm{p}=0.887$ & $\begin{array}{l}17.63 \\
(3.07)\end{array}$ & $\begin{array}{l}15.80 \\
(1.92)\end{array}$ & $\mathrm{p}=0.146$ & $\begin{array}{l}17.00 \\
(2.75)\end{array}$ & $\begin{array}{l}15.62 \\
(2.99)\end{array}$ & $p=0.065$ \\
\hline $\begin{array}{l}\text { Meaning } \\
\text { orientation }\end{array}$ & $\begin{array}{l}19.50 \\
(1.41)\end{array}$ & $\begin{array}{l}17.90 \\
(2.15)\end{array}$ & $p=0.47$ & $\begin{array}{l}19.57 \\
(1.99)\end{array}$ & $\begin{array}{l}17.29 \\
(2.52)\end{array}$ & $\mathrm{p}=0.033^{*}$ & $\begin{array}{l}19.39 \\
(1.85)\end{array}$ & $\begin{array}{l}17.22 \\
(2.90)\end{array}$ & $\mathrm{p}=0.001^{* *}$ \\
\hline $\begin{array}{l}\text { Comprehension } \\
\text { learning }\end{array}$ & $\begin{array}{l}18.75 \\
(1.49)\end{array}$ & $\begin{array}{l}16.33 \\
(1.85)\end{array}$ & $\mathrm{p}=0.001^{* *}$ & $\begin{array}{l}18.63 \\
(2.62)\end{array}$ & $\begin{array}{l}16.28 \\
(1.71)\end{array}$ & $\mathrm{p}=0.041^{*}$ & $\begin{array}{l}18.57 \\
(2.71)\end{array}$ & $\begin{array}{l}16.00 \\
(1.82)\end{array}$ & $p<0.001^{* *}$ \\
\hline Operation learning & $\begin{array}{l}18.75 \\
(1.04)\end{array}$ & $\begin{array}{l}17.07 \\
(2.02)\end{array}$ & $\mathrm{p}=0.026^{*}$ & $\begin{array}{l}19.13 \\
(2.42)\end{array}$ & $\begin{array}{l}16.00 \\
(1.62)\end{array}$ & $p<0.001^{* \star}$ & $\begin{array}{l}17.93 \\
(2.54)\end{array}$ & $\begin{array}{l}15.58 \\
(1.96)\end{array}$ & $p<0.001^{* *}$ \\
\hline Versatility & $\begin{array}{l}41.25 \\
(2.43)\end{array}$ & $\begin{array}{l}36.71 \\
(3.31)\end{array}$ & $\mathrm{p}=0.001^{* *}$ & $\begin{array}{l}40.14 \\
(3,72)\end{array}$ & $\begin{array}{l}35.88 \\
(4.23)\end{array}$ & $\mathrm{p}=0.020^{*}$ & $\begin{array}{l}39.39 \\
(3.12)\end{array}$ & $\begin{array}{l}36.32 \\
(4.61)\end{array}$ & $\mathrm{p}=0.003^{\star *}$ \\
\hline \begin{tabular}{|l|} 
Learning \\
pathologies
\end{tabular} & $\begin{array}{l}31.63 \\
(2.13)\end{array}$ & $\begin{array}{l}30.56 \\
(3.99)\end{array}$ & $\mathrm{p}=0.466$ & $\begin{array}{l}35.13 \\
(4.42)\end{array}$ & $\begin{array}{l}29.81 \\
(3.23)\end{array}$ & $\mathrm{p}=0.001^{* *}$ & $\begin{array}{l}33.50 \\
(4.54)\end{array}$ & $\begin{array}{l}28.18 \\
(4.59)\end{array}$ & $\mathrm{p}<0.001^{\star *}$ \\
\hline $\begin{array}{l}\text { Prediction of } \\
\text { success }\end{array}$ & $\begin{array}{l}77.75 \\
(3.73)\end{array}$ & $\begin{array}{l}71.76 \\
(5.92)\end{array}$ & $\bar{p}=0.008^{\star *}$ & $\begin{array}{l}73.00 \\
(3.65)\end{array}$ & $\begin{array}{l}71.63 \\
5.31)\end{array}$ & $\mathrm{p}=0.528$ & $\begin{array}{l}73.46 \\
(5.17)\end{array}$ & $\begin{array}{l}72.65 \\
(9.24)\end{array}$ & $\mathrm{p}=0.672$ \\
\hline Elaboration & $\begin{array}{l}32.0 \\
(2.83)\end{array}$ & $\begin{array}{l}30.09 \\
(3.48)\end{array}$ & $\bar{P}=0.148$ & $\begin{array}{l}32.00 \\
(4.21)\end{array}$ & $\begin{array}{l}30.07 \\
(4.09)\end{array}$ & $\mathrm{p}=0.246$ & $\begin{array}{l}35.04 \\
(2.55)\end{array}$ & $\begin{array}{l}29.83 \\
(4.51)\end{array}$ & $\overline{p<0.001^{* \star}}$ \\
\hline
\end{tabular}

B = Bangladesh; $\mathrm{S}=$ Southampton. 